\title{
INFLUÊNCIA DO TIPO DE FRUTO, PESO ESPECÍFICO DAS SEMENTES E PERÍODO DE ARMAZENAMENTO NA QUALIDADE FISIOLÓGICA DE SEMENTES DE MAMÃO DO GRUPO FORMOSA ${ }^{1}$
}

\author{
GABRIELANEVES MARTINS ${ }^{2}$, ROBERTO FERREIRADASILVA ${ }^{3}$, EDUARDO FONTESARAÚJO ${ }^{4}$, MESSIAS GONZAGAPEREIRA $^{5}$, \\ HENRIQUEDUARTE VIEIRA ${ }^{6}$, ALEXANDRE PIOVIANA
}

\begin{abstract}
RESUMO - Este trabalho teve como objetivo avaliar a influência do tipo do fruto, do peso específico da semente e do período de armazenamento na germinação e vigor de sementes de mamão, do grupo Formosa. Durante a colheita, os frutos foram classificados por tipo, em comerciável e refugo. As sementes foram extraídas manualmente, lavadas e colocadas para secar à sombra. Após a secagem, as sementes foram submetidas a pré-limpeza em separador pneumático e, em seguida, classificadas em mesa de gravidade, por peso específico, nas classes leve, intermediária e pesada. As sementes foram acondicionadas em embalagem permeável (papel multifoliado), armazenadas em câmara fria e avaliadas quanto à germinação e vigor (primeira contagem, avaliação do vigor das plântulas e envelhecimento acelerado), no início e depois de 3 e 6 meses de armazenamento. Os melhores resultados foram encontrados quando se utilizou sementes da classe pesada. A qualidade fisiológica das sementes foi mantida até o terceiro mês de armazenamento. As sementes das classes pesada e intermediária mostram alta germinação e alto vigor, podendo ser utilizadas para composição de lotes comerciáveis de sementes de mamão.
\end{abstract}

Termos para indexação: Carica papaya, beneficiamento, vigor, germinação.

\section{INFLUENCE OF FRUITTYPE, SPECIFIC SEEDWEIGHT AND STORAGE ONTHE PHYSIOLOGICAL QUALITY OF PAPAYASEEDS OF THE FORMOSA GROUP}

\begin{abstract}
The present study evaluated the influence of the fruit type, specific seed weight and storage on the germination and vigor of papaya seeds of the Solo group. After harvest the fruits were classified as small, medium or large. The seeds were extracted manually, washed and placed to dry in the shade. After drying, the seeds were processed in a pneumatic machine to separate light materials and also through a gravity table machine, where the seeds were separated into three classes: light, intermediate and heavy. The seeds were placed in paper bags, stored in a cold chamber and evaluated for germination and vigor (First Count of GT, Seedling Size and Accelerated Aging test) at the start of the experiment and after 3 and 6 months of storage. The best germination and vigor results were found when heavy seeds were used. High seed quality was preserved until the third month of storage.

Index terms: Carica papaya, seed processing, vigor, germination.

${ }^{5}$ Prof. Associado, Laboratório de Melhoramento GenéticoVegetal, UENF, Campos dos Goytacazes-RJ. messias@uenf.br

${ }^{6}$ Prof. Associado, Laboratório de Fitotecnia, UENF, Campos dos Goytacazes-RJ.henrique@uenf.br

${ }^{7}$ Prof. Associado, Laboratório de Melhoramento Genético Vegetal, UENF, Campos dos Goytacazes-RJ. pirapora@uenf.br
\end{abstract}

\footnotetext{
${ }^{1}$ Submetido em 23/03/2004. Aceito para publicação em 12/04/2005.

${ }^{2}$ Doutoranda (Bolsista do CNPq), Laboratório de Fitotecnia, UENF, Campos dos Goytacazes-RJ.gabneves@hotmail.com

${ }^{3}$ Prof. Titular, Laboratório de Fitotecnia, UENF, Campos dos GoytacazesRJ. roberto@uenf.br

${ }^{4}$ Prof. DS., Departamento de Fitotecnia, UFV, Viçosa-MG. efaraujo@ufv.br
} 


\section{INTRODUÇÃO}

O mamoeiro (Carica papaya L.) é uma planta amplamente difundida em regiões de clima tropical, encontrando, no Brasil, condições edafoclimáticas favoráveis a sua exploração econômica.

Atualmente, o Brasil é considerado o maior produtor de mamão, com aproximadamente 1,5 milhões de t/ano, sendo também um dos principais exportadores. O volume de exportações de frutos frescos, em 2000, atingiu 21.510 toneladas e representou receita de, aproximadamente, US\$17.694 milhões (Agrianual, 2002).

O mamoeiro pode ser propagado vegetativamente, entretanto, a propagação por sementes é o processo mais prático e econômico utilizado pelos agricultores nos plantios comerciais (Medina, 1995). A utilização de sementes com alta qualidade genética, fisiológica, física e sanitária é um dos fatores importantes no sucesso de estabelecimento das culturas. A qualidade fisiológica das sementes é caracterizada, principalmente, pela sua germinação, vigor e longevidade (Popinigis, 1985).

As sementes diferem individualmente em viabilidade e vigor (Souza, 1979). Assim, a identificação de características físicas, correlacionada com a qualidade fisiológica, permite a eliminação de sementes indesejáveis, com o aprimoramento da qualidade do lote.

A classificação das sementes por densidade é uma estratégia que pode ser adotada para uniformizar a emergência das plântulas, obtendo mudas de tamanho semelhante e/ou de maior vigor. Sementes de maior densidade, em uma mesma espécie, são, potencialmente, mais vigorosas do que as menores e de menor densidade, resultando em plântulas mais desenvolvidas (Carvalho e Nakagawa, 2000).

Estudando a relação entre o peso das sementes e a germinação em uma cultivar de mamão do grupo Solo, Nagao e Furutani (1986) observaram que, aproximadamente, 77\% das sementes tinham peso maior que $12 \mathrm{mg}$, sendo que $60,5 \%$, pesando mais que $16 \mathrm{mg}$. Os restantes $23 \%$ pesavam menos de 12mg e não apresentavam, visivelmente, nenhuma diferença em relação às sementes mais pesadas. Entretanto, cortes nas sementes revelaram que todas as sementes que pesavam menos de $8 m g$ não possuíam o embrião normal. Esse fato indica que a baixa germinação de sementes de mamão pode ser, em parte, atribuída ao desenvolvimento anormal do embrião em, aproximadamente, $20 \%$ das sementes.

Trabalhando com cacau, Frazão et al. (1984), mostraram que a utilização de sementes pesadas (1,9 a 2,3 gramas) possibilitou a obtenção de mudas mais vigorosas do que as de sementes leves ( 0,9 a 1,3 gramas) e médias (1,4 a 1,8 gramas). Por outro lado, Passos et al. (1976) não encontraram efeito significativo para o peso das sementes de quiabo nos testes de vigor realizados.

Equipamentos que permitem a separação das sementes, baseada no peso específico, como a mesa de gravidade, têm sido amplamente utilizados na indústria de sementes, uma vez que, melhoram a qualidade do lote através da remoção de sementes danificadas, vazias, infectadas ou outros materiais indesejáveis (Baudet e Misra, 1991).

Verificar a relação existente entre a seleção do fruto de mamão e a qualidade fisiológica das sementes pode ser de grande importância para os produtores de frutos e sementes, visando, principalmente, a utilização de frutos não comerciáveis para a obtenção de sementes.

As informações relacionadas à conservação das sementes de mamão são muito contraditórias. A maioria delas indica que a semente perde sua viabilidade em períodos relativamente curtos de armazenamento (Perez e Feder, 1981; Viggiano et al., 2000a). Entretanto, algumas pesquisas mostram que as sementes de mamão preservaram sua viabilidade por períodos de até seis anos (Bass, 1975). O presente trabalho teve o objetivo de avaliar o efeito do tipo do fruto, da classificação por peso da semente e do armazenamento na qualidade fisiológica de sementes de mamão do grupo Formosa.

\section{MATERIALE MÉTODOS}

O presente trabalho foi realizado no setor de Produção e Tecnologia de Sementes, do Centro de Ciências e Tecnologias Agropecuárias, da Universidade Estadual do Norte Fluminense, em Campos dos Goytacazes - RJ.

As sementes utilizadas foram provenientes de frutos hermafroditas de mamão do grupo Formosa, híbrido Tainung 01, colhidos nos estádios de maturação 3 (até 50\% da superfície amarela) e 4 (50 a 75\% da superfície amarela), fornecidos pela Empresa Caliman Agrícola, localizada no município de Linhares - ES.

Primeiramente, os frutos foram classificados por tipo: comerciáveis, de formato típico, sem manchas e tamanho médio e refugos, os quais consistiram de frutos deformados, manchados e de tamanho exageradamente grande ou pequeno. Em seguida, as sementes foram extraídas manualmente dos frutos e lavadas em água corrente, com auxílio de uma peneira, para retirada de tecidos placentários e pedaços de polpa. A 
sarcotesta foi removida parcialmente, em conseqüência do método de lavagem utilizado. Posteriormente, as sementes foram colocadas para secar sobre estrado telado, em um galpão, por dez dias, até atingirem teor de água, em torno, de $10 \%$.

Após a secagem, as sementes obtidas, a partir dos diferentes tipos de frutos, foram beneficiadas na Usina de Beneficiamento de Sementes, localizada na Universidade Federal de Viçosa - MG, passando primeiro por separador pneumático, para realização de pré-limpeza, onde foram retiradas as impurezas mais leves; e, em seguida, por mesa de gravidade, para classificação de acordo com o seu peso específico. Para cada material obtido foi retirada uma amostra controle, sendo que, na mesa de gravidade, foram separadas três classes de sementes: pesada, intermediária e leve. A classe leve foi descartada, devido à quantidade de semente ter sido insuficiente para realização dos testes.

As sementes foram acondicionadas em embalagem permeável e transferidas para câmara fria regulada à temperatura de $10^{\circ} \mathrm{C}$ e umidade relativa de aproximadamente $85 \%$.

A avaliação da qualidade fisiológica das sementes foi realizada logo depois do preparo das sementes para o acondicionamento e após três e seis meses de armazenamento.

Os seguintes testes e determinações foram efetuados em laboratório: peso de mil sementes, número de sementes por fruto, teor de água, germinação (TG), primeira contagem do TG, avaliação do vigor das plântulas e envelhecimento acelerado.

$\mathrm{O}$ peso de mil sementes foi determinado pela contagem, ao acaso, de oito subamostras de 100 sementes, que foram pesadas, sendo os valores do peso de mil sementes expressos em gramas, com uma casa decimal, conforme Brasil (1992). Essa determinação foi realizada apenas no período inicial de armazenamento.

Para a determinação do número de sementes por fruto, pesaram-se amostras de sementes de $20 \%$ do total de frutos de cada classe de tamanho, e a partir do peso de mil sementes, foi feito o cálculo do número de sementes das diversas classes de frutos.

O teor de água das sementes foi determinado utilizandose duas subamostras de $5 \mathrm{~g}$ de sementes, pelo método padrão de estufa a $105^{\circ} \mathrm{C}$ por 24 horas. A porcentagem de umidade das sementes foi expressa em base úmida (Brasil, 1992).

O teste de germinação foi realizado de acordo com as Regras para Análise de Sementes (Brasil, 1992), com modificações. Utilizaram-se três amostras de 50 sementes, por repetição, que foram colocadas sobre duas folhas de papel "germitest" e cobertas com uma folha, em rolos, umedecidos com água destilada, na proporção de 2,5 vezes o peso do papel. Os germinadores, do tipo BOD, foram regulados para manter a temperatura alternada de $20-30^{\circ} \mathrm{C}$ ( $16 \mathrm{~h}$ de escuro e 8 h de luz, respectivamente). A avaliação das plântulas foi feita aos 14 e 28 dias após a instalação do teste, sendo os resultados obtidos, expressos em porcentagem de plântulas normais.

A primeira contagem foi realizada conforme metodologia semelhante ao teste de germinação, sendo o resultado expresso pela percentagem de plântulas normais, observadas na primeira avaliação.

A avaliação do vigor das plântulas, também, seguiu metodologia descrita para o teste de germinação. $\mathrm{O}$ resultado foi expresso pela percentagem de plântulas normais consideradas fortes (comprimento maior que $5,0 \mathrm{~cm}$ ), observadas na primeira e última contagem.

Para a realização do teste de envelhecimento acelerado, foram pesadas, aproximadamente, 5 gramas de sementes de cada tratamento, as quais foram distribuídas, uniformemente, sobre tela de arame, no interior de caixas gerbox, contendo $40 \mathrm{~mL}$ de água destilada. As caixas, com as respectivas tampas, foram mantidas em câmara BOD, regulada à temperatura de $42^{\circ} \mathrm{C}$ por 60 horas. Após este período, as sementes foram colocadas para germinar conforme os procedimentos descritos para o teste de germinação.

O delineamento experimental utilizado foi em blocos casualizados com quatro repetições, em arranjo fatorial 2x3x3, sendo dois tipos de frutos (comerciável e refugo), três classes de sementes (controle, pesada e intermediária) e três períodos de armazenamento (0, 3 e 6 meses). Para o peso de mil sementes e o número de sementes por fruto, utilizou-se o delineamento inteiramente ao acaso com quatro repetições. Os graus de liberdade foram desdobrados, quando os efeitos das interações, foram significativas. As médias foram comparadas pelo teste de Tukey a 5\% de probabilidade.

\section{RESULTADOS E DISCUSSÃO}

As sementes classificadas como pesadas apresentaram peso de mil sementes significativamente superior em relação às sementes das classes intermediária e ao controle, porém, esses não diferiram entre si (Tabela 1).

Verificou-se menor número de sementes nos frutos do tipo refugo, provavelmente, em razão da maior quantidade de frutos de menor tamanho contidos na amostra (Tabela 2). 
TABELA1. Peso de mil sementes de mamão do grupo Formosa, em gramas, de acordo com a classe de semente.

\begin{tabular}{lc}
\hline Classe de Semente & Peso de mil sementes (g) \\
\hline Pesada & $19,23 \mathrm{a}$ \\
Intermediária & $17,19 \mathrm{~b}$ \\
Controle & $17,27 \mathrm{~b}$ \\
\hline
\end{tabular}

* Médias seguidas de mesma letra não diferem entre si pelo teste de Tukey a $5 \%$ de probabilidade.

O número de sementes nos frutos do tipo refugo foi $25 \%$ inferior ao número de sementes dos frutos comerciáveis. Segundo Leopold e Kriedemann (1975), existe uma estreita correlação entre o número de sementes no fruto e o seu tamanho final.

Na Tabela 3, encontram-se os valores do teor de água das sementes, determinados no início, aos três e seis meses de armazenamento. Os resultados mostraram que o teor de água das sementes aumentou consideravelmente após três meses de armazenamento, quando armazenadas em câmara fria regulada a $10^{\circ} \mathrm{C}$ e $85 \%$ de UR, em embalagens permeáveis. Após esse período, até os seis meses de armazenamento, o teor de água praticamente permaneceu constante, indicando, provavelmente, terem as sementes alcançado o equilíbrio higroscópico com as referidas condições de armazenamento.

Para todos os testes realizados, apenas a classe de sementes e o período de armazenamento mostraram efeito significativo. Isso indica a possibilidade de utilização dos frutos do tipo refugo para obtenção de sementes, visto que sementes obtidas a partir de frutos comerciáveis e do tipo refugo apresentam qualidade fisiológica semelhante.

Em relação à classe de sementes, os maiores valores de germinação e vigor foram encontrados para as sementes

TABELA 2. Número se sementes por fruto, de acordo com o tipo de fruto de mamão do grupo Formosa.

\begin{tabular}{lc}
\hline Tipo de Fruto & Número de Sementes \\
\hline Comerciável & $613,0 \mathrm{a}$ \\
Refugo & $466,2 \mathrm{~b}$ \\
\hline * Médias seguidas de mesma letra não diferem entre si pelo teste de Tukey \\
a 5\% de probabilidade.
\end{tabular}

TABELA3. Teor de água (\% b.u.) das sementes, de acordo com o tipo de fruto e período de armazenamento.

\begin{tabular}{lccc}
\hline \multirow{2}{*}{ Tipo de Fruto } & \multicolumn{3}{c}{ Período de Armazenamento (meses) } \\
\cline { 2 - 4 } & $\mathbf{0}$ & $\mathbf{3}$ & $\mathbf{6}$ \\
\hline Comerciável & $9,8 \mathrm{Ba}$ & $16,5 \mathrm{Aa}$ & $17,4 \mathrm{Aa}$ \\
Refugo & $9,6 \mathrm{Ba}$ & $15,5 \mathrm{Aa}$ & $16,9 \mathrm{Aa}$ \\
\hline
\end{tabular}

* Médias seguidas de mesma letra maiúscula na mesma linha e minúscula na coluna não diferem entre si pelo teste de Tukey a 5\% de probabilidade. classificadas como pesadas, seguidas das intermediárias e do controle, que não diferiram entre si (Tabela 4). Neste caso, o uso da mesa de gravidade, mostrou-se eficaz para classificação de sementes de mamão Formosa. Apesar das sementes da classe pesada terem sido consideradas de melhor qualidade fisiológica, em razão da maior germinação em relação às classes intermediária e controle, isto não significa que as sementes destas classes não sejam apropriadas para a comercialização, uma vez que as sementes da classes intermediária e controle apresentaram valores dentro do padrão de comercialização, acima de $65 \%$.

Durante o período de armazenamento, as sementes provenientes dos frutos comerciáveis mostraram maiores valores de germinação no terceiro mês, seguidos do período inicial e sexto mês (Figura 1). Resultados semelhantes foram encontrados por Aroucha et al. (2003a) e Viggiano (1999), onde as sementes apresentaram maiores valores após quatro meses de armazenamento.

Foram encontrados valores de germinação no período inicial de até $86 \%$, o que diverge dos resultados encontrados por Viggiano et al. (2000b) e Aroucha et al. (2003a), que observaram baixa germinação (entre 9 e 20\%) de sementes

TABELA 4. Valores médios, em percentagem, de germinação (G), primeira contagem $(\mathrm{PC})$, avaliação do vigor das plântulas (AP) e envelhecimento acelerado (EA), de acordo com a classe de semente.

\begin{tabular}{lcccc}
\hline Classe de Semente & G & PC & AP & EA \\
\hline Pesada & $76 \mathrm{a}$ & $58 \mathrm{a}$ & $57 \mathrm{a}$ & $96 \mathrm{a}$ \\
Intermediária & $68 \mathrm{~b}$ & $51 \mathrm{~b}$ & $51 \mathrm{~b}$ & $81 \mathrm{~b}$ \\
Controle & $69 \mathrm{~b}$ & $51 \mathrm{~b}$ & $50 \mathrm{~b}$ & $81 \mathrm{~b}$ \\
\hline
\end{tabular}

* Médias seguidas de mesma letra não diferem entre si pelo teste de Tukey a $5 \%$ de probabilidade.

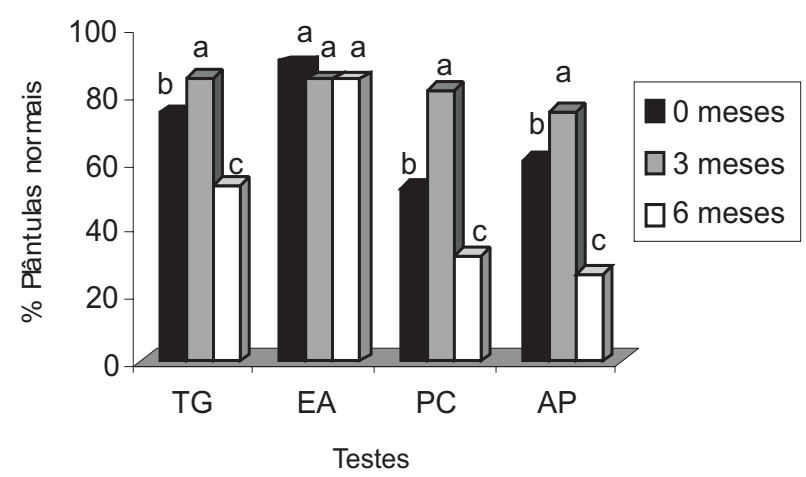

FIGURA 1. Porcentagem de plântulas normais de sementes de mamão durante o período de armazenamento, de acordo com os testes de germinação (TG), envelhecimento acelerado (EA), primeira contagem (PC) e avaliação do vigor de plântulas (AP). 
de mamão, recém extraídas dos frutos. Yahiro (1979) e Yahiro e Oryoji (1980) também verificaram que sementes de mamão, recém extraídas dos frutos, apresentaram baixa germinação, mesmo com a remoção da sarcotesta, indicando uma provável dormência pós-colheita.

Aos seis meses de armazenamento, observou-se decréscimo na germinação e no vigor das sementes. Isso confirma resultados obtidos por Viggiano (1999), onde as sementes de mamão armazenadas por quatro meses, apresentaram redução na germinação e no vigor.

Em relação ao teste de envelhecimento acelerado, para todas as classes de sementes e durante todo o período de armazenamento, as condições utilizadas para o teste $\left(42^{\circ} \mathrm{C} /\right.$ $60 \mathrm{~h}$ ) funcionaram como um tratamento de pré-germinação, promovendo quebra de dormência das sementes. A Tabela 4 e a Figura 1 mostram que a porcentagem de germinação após o envelhecimento acelerado foi superior ao teste de germinação. Resultados semelhantes foram encontrados por Aroucha et al. (2003b) e Balbinot et al. (2003), quando utilizaram o envelhecimento para sementes de mamão nas condições de $42^{\circ} \mathrm{C} / 48 \mathrm{~h}$ e $42^{\circ} \mathrm{C} / 72 \mathrm{~h}$, respectivamente. De forma semelhante Pinto et al. (2003) concluíram que as condições de envelhecimento acelerado $\left(42^{\circ} \mathrm{C} / 96 \mathrm{~h}\right)$ e présecagem $\left(60^{\circ} \mathrm{C} / 72 \mathrm{~h}\right)$ foram eficientes para a superação da dormência de sementes de arroz.

\section{CONCLUSÃO}

As sementes estratificadas na mesa de gravidade correspondentes às classes pesada e intermediária mostram alta germinação e alto vigor, podendo ser utilizadas para composição de lotes comerciáveis de sementes de mamão.

\section{REFERÊNCIAS}

AGRIANUAL. São Paulo: Argos, 2002. 536p.

AROUCHA, E.M.M.; SILVA, R.F.; OLIVEIRA, J.G.; BALBINOT, E. Avaliação da germinação e vigor das sementes se mamão (Carica papaya L.) após armazenamento dos frutos e sementes. In: PAPAYA BRASIL: QUALIDADE DO MAMÃO PARA O MERCADO INTERNO, 1., 2003, Vitória. Resumos... Vitória: INCAPER, 2003a. 728p.

AROUCHA, E.M.M.; SILVA, R.F.; VIEIRA, H.D.; VIANA, A.P.; ARAÚJO, E.C. Influência do estádio de maturação, ambiente e período de armazenamento sobre o vigor e germinação de sementes de mamão (Carica papaya L.). In: CONGRESSO BRASILEIRO
DE SEMENTES, 13, 2003, Londrina. Anais... Londrina: ABRATES, 2003.538p.

BALBINOT, E.; COELHO, E.A.; MENDONÇA, A.V.R.; SOUZA, N.A.; SILVA, R.F. Qualidade fisiológica de sementes de mamão (Carica papaya L.) em função da posição do fruto. In: PAPAYA BRASIL: QUALIDADE DO MAMÃO PARA O MERCADO INTERNO, 1., 2003, Vitória. Resumos... Vitória: INCAPER, 2003. 728p.

BASS, L.N. Seed storage of Carica papaya L. HortScience, Alexandria, v.10, p.232. 1975.

BAUDET, L.; MISRA, M. Atributos de qualidade de sementes de milho beneficiadas em mesa de gravidade. Revista Brasileira de Sementes, Londrina, v.13, n.2, p.91-96, 1991.

BRASIL. Ministério da Agricultura e Reforma Agrária. Regras para análise de sementes. Brasília: SNDA/DNDV/CLAV, 1992. 365p.

CARVALHO, N.M.; NAKAGAWA, J Sementes: ciência, tecnologia e produção. Campinas: Fundação Cargil, 2000. 588p.

FRAZÃO, D.A.C.; COSTA, J.D.; CORAL, F.J.; AZEVEDO, J.A.; FIGUEIREDO, F.J.C. Influência do peso da semente no desenvolvimento e vigor de mudas de cacau. Revista Brasileira de Sementes, Londrina, v.6, n.3, p. 31-39, 1984.

LEOPOLD, A.C.; KRIEDEMANN, P.E. Plant Growth and Development. McGraw - Hill, 1975. 545 p.

MEDINA, M.C. Cultura. In: ITAL. Mamão: cultura, matéria-prima, processamento e aspectos econômicos. Campinas: ITAL, 1995. p.1-177.

NAGAO, M.A.; FURUTANI, S.C. Improving germination of papaya seed by density separation, potassium nitrate, and gibberellic acid. HortScience, Alexandria, v.21, n.6, p. 1439-1440, 1986.

PASSOS, F. A.; MAEDA, J. A.; BERNARDI, J. B. Vigor de sementes de quiabo. 1 - Teste de campo. Campinas: IAC, 1976. 12p. Circular

PEREZ, M.; FEDER, Z. Germination of two papaya varieties effect of seed aeration, k-tratament, removing of the sarcotesta, high temperature, soaking in distilled water and age of seeds. Journal of Agricultural of the University of Puerto Rico, Puerto Rico, v.64, p.173-180, 1981.

PINTO, J.F.; VAZ, S.S.; VILLELA, F.A. Superação da dormência de sementes de arroz irrigado pelo emprego de envelhecimento acelerado e pré-secagem. In: CONGRESSO BRASILEIRO DE SEMENTES, 13, 2003, Londrina. Anais... Londrina: ABRATES, 2003.538p.

POPINIGIS, F. Fisiologia da semente. Brasília: AGIPLAN, 1985. 289p.

SOUZA, F.C.A . Classificação da semente de soja (Glycine max (L.) Merril) na mesa de gravidade e sua relação com a qualidade fisiológica e a produtividade. Trigo e soja, v. 40, p.2-19, 1979.

VIGGIANO, J.R. Influência do teor de umidade, tipo de embalagem e ambiente de armazenamento na conservação de sementes de mamão (Carica papaya L.). Campos dos Goytacazes. 1999. 67f. Dissertação (Mestrado em Produção Vegetal) - Universidade Estadual do Norte Fluminense, Campos dos Goytacazes, 1999. 
VIGGIANO, J.R.; VIEIRA, H.D.; SILVA, R.F.; ARAÚJO, E.F.; VIANA, A.P. Conservação de sementes de mamão (Carica papaya L.) em função do grau de umidade, tipo de embalagem e ambiente de armazenamento. Revista Brasileira de Sementes, Londrina, v.22, n.2, p. 279-287, 2000a.

VIGGIANO, J.R.; SILVA, R.F.; VIEIRA, H.D. Ocorrência de dormência em sementes de mamão (Carica papaya L.). Sementes Online, v.1, n.1, p.6-10, 2000b.
YAHIRO, M. Effects of seed-pretreatments on the promotion of germination in papaya, Carica papaya L.. Memorial Faculty Agriculture Kagoshima University, Kogoshima, v.15, p.49-54, 1979.

YAHIRO, M.; ORYOJI, Y. Effects of gibberellin and cytokinin treatments on the promotion of germination in papaya, Carica papaya L., seeds. Memorial Faculty Agriculture Kagoshima University, Kagoshima, v.16, p.45-51, 1980.

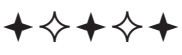

